\title{
The Moderating Effects of Human Capital and Cultural Diversity on the Link between Social Capital and Innovation Performance: A Cross-Country Study
}

\author{
Sandy Van Tran, Anh Tuan Pham, Tessa Tien Nguyen and Anh Quynh Nguyen
}

\begin{abstract}
This study contributes to current knowledge regarding the role of social capital, constituted by generalized trust, institutional trust, associational activity and norms of civic, towards country's innovation level as well as the moderating roles of nation-specific factors of human capital and cultural heterogeneity on the stated relationship, while examining the case of 51 countries around the world. Many researches have confirmed the positive contributions of social capital, human capital and cultural diversity to the development of national innovativeness. However, very few of them has ever assessed the interactions between these variables in the presence of the others in explaining country's innovation capability. By the aim of explaining the dynamics of cross-country's divergence in innovation level, the study made an effort to fill in this research gap by using countries' human capital and cultural heterogeneity as moderators for social capital in its relationship with innovation. The results highlight the positive impact of interpersonal trust and norms of civic behaviour on country's innovativeness though associational activity was confirmed with negative impact. Furthermore, human capital and cultural heterogeneity were found to weaken the link between interpersonal trust and innovation, whereas reduce the adverse effect of community involvement on national innovation performance.
\end{abstract}

Keywords - Innovation, social capital, human capital, cultural diversity, trust, norms, community involvement.

\section{INTRODUCTION}

In the new knowledge-based economy where growth depends on knowledge and information obtainment and sharing, that related to social capital such as social networks and trust has attracted great interest of researchers in recent years [1][2]. Generally, social capital is referred to "the possession of social relationships and membership in collectives, and the resources that derive from these relationships and memberships" [3]. However, the distinguished streams of research began to form when researchers started viewing the concept as a property of whether individuals or communities. The first group of scholars [4][5][6] analysed social capital from an 'external view' [2] which argues that the concept is linked to the idea of

Van Tran, Anh Tuan Pham, Tien Nguyen and Anh Quynh Nguyen, The International School of Business /The University of Economics Ho Chi Minh City, Vietnam individual actors exploring and exploiting their memberships in different groups and their connections to others. On the other hand, at an aggregate level, Putnam [7] built a foundation of understanding social capital as the 'public good' which is commonly characterized with the extent of overall associational involvement, trust or norms amongst members of a collective. Putnam's perspective has been adopted in numerous studies to explain the distinctive degrees of social capital stock in different communities and further examine social capital's possible relations to other desired regional aspects such as technological innovation as mentioned previously.

Nevertheless, the research regarding technological innovation-social capital link is centered on either the direct relationship between the two factors or the role of innovation as a third variable through which social capital affects economic growth while little effort is made on exploring more rooted matters such as potential elements that influence the strength of this relationship or specific conditions in which it occurs. There is a further lack of this research direction in studies at regional level. In this respect, as argued by many scholars and economists, human-related factors, specifically socio- demographic aspects such as age, gender, literacy, and heterogeneity in ethnicities can be regarded as appropriate moderators in this promising research path considering the massive literature evidence of them advocating innovation and growth [8][9][10] and social capital [11][12][13]. Of the commonly recognized socio-demographic fundamentals, two are particularly relevant to the successful exhibition of social capital building and innovating actions - namely, education and ethnic diversity. While education and multiculturalism have been concluded to firmly and consistently bolster the regional innovation capacity in general [4][14][15], the results of their connections with social capital seem to be mixed in a number of research. For instance, Schoon [16], Sturgis [17], and Hooghe [18] found positive link between cognitive ability and trust as well as attitudes towards society. However, Schuller [19] alleged that higher level of skills and knowledge gained by members in social groups impedes the network building activities in the community involving it. On the subject of population diversity, as stated in the research using specific social capital indicators, it seems inevitable that this 
factor does not lead to a strengthened trust level in society [20][21][22]. However, diversity might manifest a positive influence on social participation under some conditions in a number of cases [23][24]. With such dynamics relating the construct of social capital and innovation, one may question the likely not yet identified patterns within their relationship. As a result, moving beyond the current discussion in this research field, this study attempts to answer the question: "How the social capital-innovation relationship varies across different nation-level specific socio-cultural backgrounds such as education and ethnic diversity?".

To address this research question, the current study adopts the quantitative approach at the national level with the scope covering 51 countries in all five continents. Data was gathered from reliable sources such as World Bank, World Value Surveys and UNESCO Institute of Statistics. The structure of this paper includes the existing literature on innovation, social capital and their associations with education and diversity, a summary of the methodological approach, the findings, the discussion, an outline of theoretical and practical implications, research limitations, and suggested further research.

\section{II.THEORY AND HYPOTHESIS}

\section{A. Innovation}

In simple terms, innovation can be defined as "the exploitation of new ideas" [25] with outputs as products, services, techniques or practices [26] at organisational level. Freeman [1] explains that the successful diffusion in a commercial sense determines the meaning of innovation with the basic elements: (1) the innovation itself, (2) the potential adopting population, (3) their decision-making process and (4) and the flows of information involving the innovation between the innovator and the adopters all which decide the rate of diffusion that the more useful functions the innovation has, the faster and more widely it is diffused. A non-economic factor associated with the adopters can be their intensity in the use of communication channels. Hence, the diffusion of innovation is vastly impacted by economic and social characteristics of the society [4].

Bush [6] first attempted to propose that innovation is rather discussed as a process with the first formulations of the 'linear innovation process' emphasizing on the explicit knowledge achieved in research process whose output can be transferred to the next phase as inputs with unidirectional patterns. Other scholars then encouraged the theory that innovation should be seen as much a social as a technical process driven by the act of reciprocal learning between innovators and their environment with the emphasis on creating and combining knowledge collected from multidirectional flows of information with a complex feedback systems and relationships involving broad collection of actors [27][28][29]. They point out the important of promoting interactive learning and multidirectional information and considers the neglected factor of innovation external environment with the information amassed present both internal and external views of the process and thus the knowledge output becomes broader and more objective. As seen from an aggregate point of view, innovation can be presumed as a 'locally embedded process taking place within the regional innovation environment' [30] consisting of innovation networks aiming to enhance the innovative capability and performance of the system [31]. The development of regional innovation can be related to the nonlinear innovation process in terms of the integration of diverse information inputs derived internally or externally allowing new knowledge to be combined and problems to be solved more efficiently and the networks between actors within the regional innovation systems as a complicated communication and feedback tools. Regional or national innovative capability is equivalent to the joint innovative capacity of the organisations of the region or nation. A vast amount of present theoretical frameworks and concepts are studied to help analyse the dynamics in the creation of regional innovative capability: innovative milieu [32], industrial districts [7] territorial production system [33]; regional innovation systems [34] and learning regions [35], national innovation systems [27][36] etc. with the emphasis on the importance of network leadership and institutions [37][38]. The attention of researchers in this field are drawn by the role of the milieu in facilitating the innovative performance of organisations in certain regions with its two mechanisms of 'collective learning process' and 'dynamic uncertainty reduction' [32] to promote knowledge and best practices diffused speedily, thus boosting the innovative capacities of actors and decrease the degree of uncertainty by organising interdependence in terms of function and information [32]. Christ Freeman [1], in his work that explained the variations in innovation success across different countries, first pointed out the significance of the system within a country in contemplating the process of learning and innovation. Lundvall [27] and Nelson [36] further conclude that the drivers for technological change and innovation in a nation relate to its specific factors such as education, communal reinforcement for industrial innovation, or culture [7]. Herein, much emphasis is on the role of socio-institutional environment, interactivity and non-linearity of the innovation process and collective learning and networks are the sources of innovation.

\section{B. Social Capital}

Social capital aspects have been explored in two different yet related research streams - the individual level and the aggregate level. The individual-level social capital refers to "the networks an individual or firm belongs to". In the organisational view, the concept of social capital at individual level is built on the foundation of one resource-based view extension - the relational view [19]. This so-called 'external view of social capital' [2] holds that a firm does not generate its competitive advantage only from organisational resources but also from difficult-to-imitate capabilities rooted in multidirectional network relationships [39]. The recent study [40] indicates that social capital is seen as the total of the actual and possible embedded resources derived and available 
from the network of relationships with impersonal arrangements of the linkages in the network, the relational dimension associates with personal relationships between the network members such as friendship or respect and the social assets namely shared values, perceptions and judgements. For this, scholars point out valuable effects of social capital: (1) lessening the need of monitoring and reducing the redundant information, thus lowering transaction costs and creating more economical and productive methods for distributing information and (2) encouraging cooperative behaviors that give opportunities for adaptive and creative solutions to problems.

Social capital of a nation or region is suggested to determine the success of regional governments and economic performance [41][42][7], referred to the 'public good' or 'collective good' Putnam [7] explaining that regions with more horizontal social relationships which are based on trust and shared values experience higher degree of participation in social collectives and thus higher level of social capital. He indicates that trust encourages cooperation and cooperation then breeds trust. Referring to the concept of civil engagement, Putnam indicates that civic participation inspires the members to develop a sense of "cooperation, solidarity and publicspiritedness" which more effectively constrains opportunism and gives the answer to problems of collective actions deepening the potential costs to a traitor for any opportunistic transaction. Moreover, participations in civil organisations can assist the progress of communication and improves the diffusion the trustworthiness of individuals. Research by Boix and Posner [43] notes the process through which social capital is converted into greater macro performance and conclude with several points. First, the need to reinforce compliance can be reduced with the presence of complicated and costly systems of enforcement created by social capital. Second, it stimulates the articulation of collective demands so that they present collective benefit. Finally, the resources devoted to supervising can be funded in more beneficial businesses once social capital encourage individuals not to engage in opportunism. However, one may find that the collective benefits are impeded by some small interest groups with no enthusiasm contributing toward the society but have motivation to take part in costly and destructive profit-seeking behaviours such as corruption or lobbying [44]. The harm becomes more detrimental to the overall economic performance when these groups grow larger with more power.

Since the current study is a cross-country investigation, in line with a growing body of research in the field [45][46], the perspective of regional social capital from Putnam [42] is adopted which relate to features including trust, associational activity, and norms of civic behavior.

\section{Social capital and innovation}

Reference to [47] reveals that economic performance is generally induced by social capital through several possible mechanisms with positive impacts on the productivity of the network by lowering uncertainty in terms of specialisation of labour, lessens the transaction and coordination costs. More importantly, it influences the innovation processes by determining the amount and the diversity of knowledge available to an actor. Through the authors' definition of innovative capability as the ability of an actor to exploit and rearrange existing resources to enable innovating, it can be argued that social capital may be considered as one of the resources of the actor among other capitals such as economic, physical or intellectual which should be effectively used to produce innovations based on the social relations and opportunities acquired. The role of social capital when moving the scope of innovative capability to a regional level is not only one of the resources but becomes the systems embedded in the network of that innovating community that allows members to have access to the material, financial and intellectual resources of the whole collective or even beyond the collective [30] In their work, Tura \& Harmaakorpi term this systems of network the 'regional innovation networks'. They argue that the regional innovation networks are not only referred to a network of isolated actor but a network of various actors. It is typically larger, more heterogeneous and serves a common purpose that contributes to the success of the whole region, not for any one's own success. Reference to [48] suggests that regional innovation networks enable members to join in a non-linear learning process with actors from different fields and combine knowledge or uncover new ways of conducting for more ultimate innovations and solutions. For this network system to perform productively and consistently, there is a great need of aligned goals with reasons and motives to achieve common benefits from long-term, resourcegenerating processes [30]. This is why the importance of social capital is emphasised when it offers assets as well as mechanisms such as civil associations and norms of civic behaviors.

\section{Trust}

Trust is generally considered as one's perception and interpretation of the other's expected trustworthiness. In a study of [49][19] found that the concept of trust may be constructed as the certainty that a partner will not take advantage of the vulnerabilities of the other for their personal purposes [41].

Various typologies of trust have been introduced. Reference to Luhmann [50] distinguishes two main types of trust: (1) the micro-level trust refers to the emotional association between individuals, characterised by basic and narrow group connections; (2) the macro-level trust is comprised of more abstract relationships related to the functioning of organisational systems such as legal, political and economic. Besides Luhmann, [51] advanced the trust in three forms: deterrence-based, calculus-based, and relational-based. Deterrence-based trust concerns practical considerations and the belief that specific penalty systems are in place. Parties are then obliged to cooperate and expect reciprocation with the fear of costly sanctions if breaching the contract. Calculusbased trust, however, results from the rational choice and 
objective information relating to the competence and reliability of the partners. Finally, relational-based trust is the product of repeated experience of interactions that embrace norms of reliability, dependability and reciprocity with elements such as emotions and interpersonal care. Based on the pattern seen from across these typologies, a number of researchers interpret trust in two main forms: (1) interpersonal trust which captures the ideas of micro-level trust, calculus-based and relationalbased trust and (2) institutional trust which apprehend the meaning of macro-level and deterrence-based trust [37][14]. Therefore, for the purpose of this study, the concept of trust is understood by two components: (1) interpersonal trust - trust in individuals and (2) institutional trust - trust in environment.

Luhmann [50] and Parsons [52] view trust as fundamental to social order and social complexity reduction, that greater trust in a society diminishes the need to establish institutional mechanisms to overcome opportunistic problems in transactions. Trust in some cases can serve as a substitute of contracts or even more effective than contracts when dealing with complex transactions. Research on the influence of interpersonal trust has shown its close link to innovation, both within organisations and in inter-organisational context. First, at firm level, trust in individuals reduces the need for rigid controlling activities that usually hampers creative thinking and idea generation within an organisation [53][54]. Consequently, it results in time and financials saved from monitoring. If entrepreneurs must dedicate time and resources to supervise possible malfeasance by employees or partners, they have less time and resources to innovate. Second, at regional level, a high level of this trust between organizations within a country induces the exchange of confidential information by lessening the risk that one party will exploit this information for opportunistic purposes [45]. Hence, trust can strengthen regional innovation capability by maximising the amount and the diversity of resources available to any innovating actor who is a trusted member of the community. In terms of institutional trust, it is noted that when the institutions in the environment are perceived as effective in assisting transactions and defending individuals against any violation of trust, people are more willing to interact, establish networks and accept risks in their businesses with others [37]. For example, in communities where governing systems issue persuasive patent-registration and protecting laws, one may be more likely to join in relations such as joint $R \& D$ projects, expecting that there are trustworthy systems to constrain or intimidate any opportunistic partner. Inversely, when individuals believe that such supporting mechanisms are ineffective or, even worse, not developed, they may tend to narrow their scope of interactions to those partners only within their interpersonal trusting relationships. Accordingly, two hypotheses are offered as followed:

Hypothesis 1. The level of interpersonal trust within a nation is positively related to the nation's level of innovation performance.
Hypothesis 2. The level of institutional trust within a nation is positively related to the nation's level of innovation performance.

\section{Associational activity}

As defined by Knack and Keefer [45], "associational activity is the general tendency for individuals in society to be active members in groups and voluntary organizations". Associational activity often gives individuals access to contacts in their own community even those at the regional level, whose backgrounds and professions are varied. The work of Putnam [42] in Italy argued that the voluntary participations encourage their members to adopt habits of mutual support and solidarity. In relation to innovation, social associations reinforce the speed of knowledge creation and exchange to combine and generate creative products or solutions [55]. Moreover, the regional innovation's characteristic of diversity requires a high level of inter-group connections within the region to maximize the potential of its social capital. Associational activity with involvement in different field groups makes an actor become connections between groups which foster innovation through memberships in multiple organisations by increasing the exposure to different ideas and providing various sources of information or any other form of capital. This is supported by the research of [56] finding that the entrepreneurs' personal and professional relationships with influential individuals contribute significantly when looking for capital for project funding. Also, [29] a lot of owner-managers of small businesses can use their associations with organisations such as Small Business Federations or Chambers of Commerce and informal organisations to accumulate a source of valuable ideas and business relationships. Accordingly, a hypothesis is formed as followed:

Hypothesis 3. The level of associational activity within a nation is positively related to the nation's level of innovation performance.

\section{Norms of civic behaviours}

Norms of civic behaviour refer to "the extent to which people in a society tend to cooperate and put self-interest under that of the society" [45]. With the presence of such norms, predatory, opportunistic behaviours are limited and public good exhibition is promoted. It is stated that norms of civic behaviour and associational activity often accompany in some cases since individuals who are devoted to the local community's benefits may be more inclined to engage in communal activities to contribute to the ultimate goal that is best for all [37]. However, these two notions are not similar and do not necessarily progress in the same direction. For example, the distinction between the two dimensions is made clear by Olson [44] viewing that some regional or national associations are founded possibly to serve their members' personal purpose instead of that of the local community or society which can hinder a society's common development. Briefly, being a member of an association may offer instruments for demonstrating civic dedication, the important 
point is that whether individuals capture the opportunity for improving the public good or for their personal purposes. The concept of 'being civic' was tested at both firm and societal level. As an example, Kilkenny [57] observed that the community had a more positive outlook of business performance among the small towns in the United States when civic participation existed. Similarly, research by Putnam [42] suggests that particular areas within Italy have reached greater economic achievements compared to the rest due to higher civic commitment. At the national level, Knack and Keefer [45] observed that some countries have experienced more economic growth in the 1980s compared to others when people practiced more powerful civic norms. As regards to their influence on innovation, numerous researchers have reported on the more intensive exchange of ideas and knowledge as a result of cooperative behaviours.

Another case when cooperative norms can maximise their advantages is the partnership in the open innovation model, where companies adopt integrated processes to acquire and transfer external knowledge into the firm or exploit commercial value of internal knowledge by transferring outside or both simultaneously [58] while engaging with various external actors - suppliers, consumers, universities, and competitors - to enhance innovation capabilities and competitiveness is critical in such model of partnerships [59]. However, Enkel [58] mention a number of risks and barriers that inhibits innovating actors from profiting on open innovation practices such as the loss of knowledge and control, higher coordination costs, higher complexity, difficulties in finding the right partners, insufficient time and finance, etc. Therefore, given the positive effects of ideas and resources free flows on innovation, the following hypothesis is advanced:

Hypothesis 4. The level of norms of civic behaviour within a nation is positively related to the nation's level of innovation performance.

\section{D.Influence of nation-specific factors on innovation}

1. Human capital and innovation

The concept of human capital was widely recognised as skills, knowledge, abilities, experience, aptitude, and training [60][61]. In Becker's view, human capital is directly useful in the process of production by boosting a worker's productivity in all tasks, though possibly differently in different tasks, organizations, and contexts. The author emphasises the importance of investing in human capital, or more particularly, education and training. Gardner [62][63] argued that human capital should be considered as a multi-dimensional concept which include many types of skills such as mental and physical skills while [64] and [60] understand human capital as the ability to adapt especially in situations when the environment is changed. Empirically, Glaeser [65] found human capital to be significant in explaining the growth of urban regions. More specifically, education attainment of citizens closely relates to their income. It was found that growth is positively linked to the average years of school attainment at the secondary and higher levels.

In the previous review on the concept of innovation, it is concluded that innovation process emerges as being driven by certain social factors within the environment in which it operates and human factor is apparently a powerful element to be consider in any innovating context. Likewise, a key new insight into the social network theories of innovation is that knowledge and learning play increasingly more vital roles in reinforcing innovation [66]. Much literature states that knowledge availability is a primary explanatory variable in innovation either for organisation or a geographical space [67][68]. The process of globalisation has made knowledge more accessible than ever with the extraordinary enhancement of communication and created opportunities for nations to approach more advanced technologies through knowledge spill-overs. With the opportunities equally open to all nations, it is the ability to learn of a country that determines its success through the level and the quality of knowledge acquired as well as how well it is applied to the process of innovation [27]. This is considered by Becker [15] as the main function of human capital in advocating national growth in general and national innovation performance in particular with useful learning ability to facilitate the creation and diffusion of innovation by ensuring the effective process of absorbing and imitating new technologies. This condition also explains why the development of education and training system often takes place along with technological progress in countries with outstanding economic performance [37][61][69][70].

Apart from these macro-economic effects, higher quality human capital also yields better results in innovation management and teamwork in organisational contexts. Numerous researchers indicate that teams with members that possess greater cognitive ability produce more effective and creative solutions to problems [71][72][73], backed up by a substantial amount of empirical work. For example, the study conducted by the work [12] observed the relationship between the socio-demographic composition of the top management and the innovative capability of firms with the examination of 199 companies. The results confirm the positive impact of education level of managerial members on the firms' innovation performance. The similar evidence is also found in research conducted in general work groups that exhibit higher and more diverse knowledge [74][75]. The authors argued that groups with higher level and wider range of knowledge and ability are suggested to conduct more efficient and effective problem-solving processes as well as generate higher quality, more original and creative ideas for new products or solutions [76][77].

Finally, appropriately invested human capital may induce entrepreneurship, according to [60], thus stimulates the development and diffusion of innovation [9][10]. The most well-known economic concept of entrepreneur, introduced by Schumpeter [78], emphasised the entrepreneur's role as innovator that brings in 'new combinations' - new products, 
services, methods, markets, sources of supply - triggering a process of 'creative destruction' and thus is a source of economic changes. Entrepreneurs are also suggested to own exceptional 'alertness' to profit opportunities such as new products or production process and pioneer in filling the market gap before others [57]. However, through a humancapital approach to entrepreneurship, Schultz [60] conceives the notion as a human behaviour: the ability to adjust and reallocate resources in reaction to changing circumstances. Therefore, entrepreneurial ability is a form of human capital which, like other forms of human capital, can be improved through education, training and experience, specifically entrepreneurship education, as an example. Not only entrepreneurship-specific training, but higher level of general education is also reported to have significant reinforcement on entrepreneurial intention and ability, and consequently innovation [38][79]. The productive impacts of human capital on entrepreneurial intention are also well verified by the extensive amount of research on students' entrepreneurial intention and their education level with observed data from various countries such as the United States, The United Kingdom, China, Singapore, Portugal, Turkey, Malaysia, etc. [80][81].

\section{Cultural diversity and innovation}

Cultural diversity generally refers to 'the range of citizens with different origins, religions, and traditions living and interacting together' [4] which is brought by migration [32]. The question whether cultural diversity carries economic costs or benefits is yet a highly disputed questions among scholars. Most drawbacks of ethnic heterogeneity pointed out by a large conceptual and empirical evidence relate to its negative societal impacts on social cohesion, capital and institutions which will be elaborated more detailed in the next section. The variety of ideas and abilities carried across by immigrants, and more importantly, their composition appear to be crucial factors in promoting technological progress in the destination country [4]. In fact, particularly at the micro level, diversity within a team may enhance its performance as diverse skills, experiences, and abilities of members of various backgrounds are utilised in the daily interactions leading to increased overall productivity [82].

However, the role of cultural diversity as the driver for creativity as well as the construction of certain 'creative city' or 'creative metropolis' has indeed proposed more systematic approach to the promotion of innovation in regions and nations. Creativity is defined as a problem-solving capacity, a way to "look afresh on problems and possibilities" [83] that can provide with original and productive solutions. In the international debate on innovation development, creativity is highlighted as the new key resources in organisational competitiveness. However, creativity is not only important for individual and organizational performance, but also for economic success and social development at a societal and global level [67]. Along with this notion, concepts like the "creative economy" [84], "creative industries" [85], and "creative class" [86] are dominating and restructuring contemporary theoretical discussions about regional development. Creative industries and creative class are also argued to be a source of innovation in the knowledge economy, with the limitless supply of ideas for potential breakthrough products across a range of industries [67]. The reference to [87] propose that creativity has a social dimension on which personal traits and cultural differences can affect and consider 'tolerance, open-mindedness and the boundary blurring ability' as qualities in creative thinking which can be achieved through experiencing the culturally diverse environment [86]. According to the author, increased cultural diversity leads to higher tolerance among members in a region, creates attraction for highly-educated and creative labour; hence, the resulting environment becomes appealing to more high-technology firms and investors.

In spite of the perks of more open-minded perspective and highly creative results of teamwork that cultural diversity induces, it is undeniable that working in multi-cultural groups is complicated. It has been discovered that employees have a particularly difficult time making the necessary personal arrangements to function with others of different national cultures [34], especially in their first participation. Crosscultural teamwork skills are not competencies that individuals automatically have but require experiences and training but need given adequate time to be built [88][89][90].

\section{E. Moderating effects of nation-specific factors}

\section{Human capital and social capital}

As the modern world has become a "knowledge society", human and social capital emerge to represent the social elements that determine the success of the innovation process and thus growth, regardless at organizational or national level [92]; Uzzi, 1996). In terms of social capital's unidirectional influence on the stock of human capital, the famous work of Coleman [31] emphasises that social capital in the family and the community play certain roles in the creation of human capital in the rising generation. As the author argued, children's educational outcomes are higher in families with greater social capital exhibiting through stronger emotional connections between members, more physical presence of parents, more attention given to the children, and their open expectations of the children's educational achievements. Inversely, children may tend to perform poorly or even drop out of school when there is a severe lack of familial social capital. He also points out that the adult community surrounding the school, which stresses the importance of young generation's education, may foster the mind set of youth development and discourage the act of dropping school [31]. Furthermore, the levels of active participation in civic life or in other networks may be seen as informal approach of learning with the acquirement of skills is through learning-by-doing [19]. As noted in an analysis of Schuller [19], technological innovation and human capital are "both very powerful in their own terms, and essential features of prosperity, but they cannot be taken out of their contexts of social relationships". The 
previous review on regional innovation and human capital indeed underscores the social side of these two concepts. Empirically, Han et al. (2013) found the cohesion and trusts among team members to be advantages to the process of knowledge integration making the team's overall human capital as well as creativity to increase, and thus reinforce organisational innovation. Through the revision of these demonstrations, the benefits of social capital on human capital and technological progress in organisations or regions seem apparent and well documented by scholars in the field. However, in reverse, whether the relationship between social capital and innovation performance is conditioned by a country's stock of human capital remains an unexplored matter.

The presence of higher quality human capital may result in different moderating effects on innovation outcomes' relationship with various social capital dimensions namely interpersonal trust, institutional trust, associational activity, and norms of civic behaviours. First, the impact of interpersonal trust among community members on innovation performance should be stronger when individuals are more highly educated. Since interpersonal trust allows more open flows of information that benefit actors in the relationship in terms of new and valuable information which cannot be obtained without trust. If both actors are more competent, regardless they are leaders or ordinary individuals, the knowledge exchanged can be utilised more effectively and the transmission process can be upgraded for further interactions, making the interpersonal relationship extensively useful for developing innovation in the future. Ceteris paribus, the effect of interpersonal trust on innovation performance may become stronger, the higher the level of human capital:

Hypothesis 5A. Human capital positively moderates the positive relationship between interpersonal trust and innovation performance.

The next argument is that the link between institutional trust and innovation outcome is stronger in countries with higher quality stock of human capital. The primary function of institutional trust is that it lessens the environment-related uncertainty perceived by innovating actors. In the context of innovation, it constitutes the actors' attitude and belief that a proper regulatory system exists with reliable innovationfriendly policies and effective and fair structure of sanctions to protect their interest against opportunism or any selfish conspiracy. This form of trust spurs initiations for innovation and willingness to invest as well as searching for potential joint-venture partners. Highly-educated individuals with superior knowledge and skills are more likely to thoughtfully seek for excellent partners and have brilliant criteria to pick the most appropriate candidate, leading to higher probability of innovation success compared to lower competent actors, despite they both trust and are prone to innovating actions. Therefore, the positive effect of institutional trust on technological progress is strengthened in countries with greater stock of human capital.
Hypothesis 5B. Human capital positively moderates the positive relationship between institutional trust and innovation performance.

Technological progress is often associated with the level of knowledge spill overs nowadays. Cohen and Levinthal [30] first illustrate its importance in promoting a country's technological progress and growth through inducing complementarities in R\&D endeavours and raises the need for certain learning ability called the 'absorptive capacity'. Knowledge spill-overs generally refers to the exchange of ideas among individuals. Therefore, the first and foremost condition for knowledge spill overs to occur is the presence of interactions between multiple actors which can be assisted by the participation in groups. Moreover, as discussed in the previous section, human capital intensifies the effects of knowledge spill overs by providing a higher level of absorptive capacity. With more superior ability of information filtering, processing, and more effective analytical mechanisms, highly-educated members can consequently speed up the process and create better synergy of higher quality ideas [15] that are derived from group participations. As a result, associational activities performed by members of a society generate more advanced intellectual outcomes as more valuable inputs in its innovation process. Ceteris paribus, the effect of group participation on innovation performance may manifest more strongly, the higher the level of human capital:

Hypothesis 5C. Human capital positively moderates the positive relationship between associational activity and innovation performance.

Societies that have highly-educated members are more desirable contexts for stronger effects of cooperative norms on the degree of technological creations. In general, the effect of intellectual exchange from social cooperation may be increased in the society with greater stock of human capital since information quality is more concentrated and the interaction channels can be improved and faster, considering the competent human capital engaged. Likewise, talented human capital constitutes ideal settings for the cooperative actions to more productively function in support of open innovation practices in firms. Due to the fact that open innovation approach exhibits intensive both inwards and outwards flows of intellectual properties in one firm or two firms may commit to a reciprocation of knowledge, there are complications attached to the implementation and management processes. Although cooperative attitude of partners makes the venture less strained through the tendency to brace mutual benefits from both sides, managing open innovation projects to yield the best results can be overwhelming and troublesome. Therefore, the presence of a body of skilful and capable employees or leaders will help relieve the companies of the technical burden, address communication problems to upgrade overall productivity and thus the innovation outcomes. In favour of this argument, Jang (2015) also found that entrepreneurs' human capital to positively impact the intensity and success of firms' open innovation practices. For that 
reason, higher quality human capital may enhance the existing positive effect of norms of civic behaviour on innovation performance.

Hypothesis 5D. Human capital positively moderates the positive relationship between norms of civic behaviour and innovation performance.

2. Cultural diversity and social capital

National culture influences the level and functions of social capital. Dimensions of national culture, such as uncertainty avoidance and individualism, are reported to differently affect human behaviour and practices across countries [99]. For example, differences in national culture are found to describe the adoption of technologies and innovation (Straub, 1994), organizational practices [92], as well as different values among individuals in the same profession (Kankanhalli et al., 2003). Scholars also found the diverse composition of culture within a particular country to variously impact its economic performance (Goren, 2014; Montalvo \& Reynal-Querol, 2005), level of technological progress [4], productivity [82], social cohesion and trust [4].

Extensive research on the link between a country's social resources and its cultural heterogeneity have pointed out the negative nature of this relationship. Putnam (2007) and a research team initiated an intensive study with one of the most significant findings was "residents of ethnically diverse communities are less likely to trust people in their neighbourhoods, the clerks where they shop, the people they work with, and even people of their own ethnic group". Another claim is that residents in more diverse communities tend to be more personally isolated, have fewer friends and have less sense of community with their friends (Saguaro Seminar, 2001). Although most research asserts the unfavourable relationship between diversity and social health, Hooghe [18] points out that there is a variance in the way different societies deal with ethnic diversity and the relationship cannot be assumed for all societies. Furthermore, the author mentioned the role of interactions between culturally diverse groups that may moderate the situation in different communities.

Interpersonal trust in relation to the promotion of innovation is characterised by the facilitation of information transmission, reduction of resources devoted to supervising other actors such as employees, suppliers or partners. Possessing the pool of multifarious perspectives and interpretations, individuals in a culturally heterogeneous society, when working as multi-cultural teams, are proposed to increase the variety of insights, alternatives and approaches; thus more likely to contribute cutting-edge innovations. If highly-educated human capital enables knowledge exchange to be more cost-effective with exceptional materials, culturally diverse human capital widens the bound of knowledge an innovating actor can attain [3]. Regardless of the resources they generate, it is said that some extent of doubt might exist among culturally differing individuals concerning the logic of appropriateness and the accepted values and norms of the different cultures, especially when working in multi-ethnic groups. A paper by Pettigrew (1998) argued that the relationships between culturally different individuals and groups may be negatively influenced by stereotyping and threats created by fears of losing economic and political advantages to members in other groups. However, Gundelach and Freitag (2012) discover that for culturally different individuals who experience interethnic contact, there is a tendency to manifest higher degree of tolerance, although the negative impact of diversity remains. For innovating firms that choose to benefit from multi-cultural groups, this issue imposes a degree of resources for training and initial monitoring for achieving the best synergy and innovations. The resources saved through perks of interpersonal trust now may be allocated for this purpose and scarify their initially intended contribution for innovation endeavours. Eventually, heterogeneous human capital may either strengthen or weaken the positive effect of interpersonal trust on innovation.

Hypothesis 6A. Cultural diversity has neutral effect on the positive relationship between interpersonal trust and innovation performance.

The main impacts of institutional trust on innovation performance is to install the confidence of citizens in the institutional systems in innovation context, encouraging actors to pursue innovative activities. Institutional trust induces the willingness to invent, invest and take part in certain business ventures by diminishing the risks attached with market environment, regulations and policies. However, in the culturally diverse settings, the impact of institutional trust is weakened. As discussed in the argument for Hypothesis 6a., the constantly existing problem of norm and value differences in highly diverse society makes culturally different individuals hesitate to work as partners, but they instead tend to choose people with familiar backgrounds [21]. Thus, they inattentively limit their partner options and may even give up when suitable partners are unavailable. This is because an actor may consider working with another from different cultural background as riskier and avoid the partnership even though he is confident in the system and willing to pursue innovation. In a more optimistic circumstance, he agrees to form the partnership yet may soon suffer from the lack of coordination due to divergent norms, values and ways of conducting. This unintentionally hinder the effect of institutional trust on innovation outcomes.

Hypothesis $6 B$. Cultural diversity negatively moderates the positive relationship between institutional trust and innovation performance.

Similar to the moderating effect explained in Hypothesis 6a, associations operating in societies with more highly diverse culture may be more likely to experience participation from individuals of more different ethnic backgrounds compared to those in homogeneous communities. Organisations with particular professional or social purposes can provide means for individuals of various cultural backgrounds to interact while coordinating for a specific mutual goal or ambition. 
Taking part in associations with multi-ethnic participation cultivates tolerance, establishes interethnic relationships and encourages transmission of valuable creative multi-perspective knowledge. The diversity of perspectives and ideas created by this varied pool of human capital is expected to generate more excellent combinations of knowledge as innovation process inputs for that society. Therefore, in more culturally diverse context, the effect of associational activity in promoting innovation is heightened.

Hypothesis 6C. Cultural diversity positively moderates the positive relationship between associational activity and innovation performance.

Societies with highly diverse culture are more beneficial settings for stronger effects of cooperative norms on the level of technological development. In general, impacts of social cooperation may be increased in the culturally heterogeneous environment since the options of intellectual combinations is further various and outcomes from problem-solving processes can be creatively improved, taking into account the greatly varied knowledge and perspectives of culturally different individuals. Likewise, culturally heterogeneous human capital may help maximise the potential of the intellectual assets stemmed from norm-based cooperation between innovating actors for more fruitful open innovation practices. The more receptive and possibly more innovative workforce participating in creative or $\mathrm{R} \& \mathrm{D}$ ventures like open innovation projects may lead to more ingenious reflections and produces breakthrough innovation outcomes. Positive prospects from such partnerships will raise confidence for more future investments in innovation that eventually induce technological progress. Therefore, in an environment with highly diverse culture, the existing positive effect of norms of civic behaviour on innovation performance may be enhanced.

Hypothesis $6 D$. Cultural diversity positively moderates the positive relationship between norms of civic behaviour and innovation performance.

\section{MethodOLOGY}

\section{A. Sample and data}

To test the hypotheses, secondary data were collected from reliable sources such as World Bank, UNESCO, World Values Survey, etc. The sample includes 51 countries from all five continents - 36 in Europe, eight in America, two in Africa, five in Asia, and Australia. To process the data, Ordinary Least Square (OLS) method was adopted with the help of STATA econometric software. Though considered a basis method, OLS is still believed to be one of the most widely-used statistical practice for analysing linear relationships.

The assessment for dependent variable - national innovation - was gathered from the World Bank's World Development Indicators (WDI) with data collected in 2010, after the period of social capital data to facilitate the analysis of the causality of the relationships implied in the study's hypotheses.

For the independent variables, the level of country's social capital was measured based on the data provided by the World
Values Survey (WVS), a comprehensive examination of social and political movement including national surveys on people's core values and beliefs in almost 100 countries around the world. The WVS data has been conducted in multiple waves of time and widely used in research to study a large number of different national social phenomena: national evolution in trust [90], education [91], politics and economic growth [14] and culture [92]. The fifth wave of the WVS carried out from 2005 to 2009 was employed in this study.

For the moderators, the secondary school's gross enrolment ratio was collected from the United Nations Educational, Scientific and Cultural Organization (UNESCO) as the proxy for human capital. Cultural heterogeneity was measured based on the work of Alesina [5] on ethnic, linguistic and religious fractionalization. This is considered one of the most ambitious and widely used fractionalization index with data for almost 200 countries in the world [93].

Finally, the control variables: countries' income inequality and total population were collected from World Bank.

\section{B. Measures}

1. Dependent variable

Because of its multi-dimensional nature, national innovation performance can refer to the inputs of technology-related investments or the outputs generated from creative activity within a particular country [94]. Several approaches to measure innovation has been suggested by prior research, such as the number of patents [17], the number of innovations [1] the R\&D expenditures [95], the use of industry-specific benchmark [96]. Also, it is argued that countries possess a large number of high-technology exporters may enhance their international competitiveness since such firms help to promote technological progress and quality of living [18][97][20]. Since all of the previously used proxies for innovation have their strengths and weaknesses [98], this study addresses innovation performance as a combination of three components: the number of patents registered in a country, the R\&D expenditures (in billions of current US dollars), and the volume of high-technology exports (in billions of current US dollars). The composite values of innovation performance were calculated as the mean standardised of its three previously mentioned components with the standardized Cronbach's alpha of 0.897 , indicating that the composite variable indeed has sufficient scale reliability.

\section{Independent variables}

Interpersonal trust is measured from the percentage of respondents that agree to the following WVS's question: 'Generally speaking, would you say that most people can be trusted, or that you cannot be too careful in dealing with people?' [94].

Institutional trust is quantified by questioning WVS's respondents on their confidence and belief in an array of organizations or institutions, such as the police, the government or churches, etc. [45]. Initially, the choice ranges from the highest of 1 (greatly believe) to the lowest of 4 (not believe at all). However, for the ease of result interpretation, 
the scales were reversed in this study so that larger values reflect greater institutional trust. The average value of all the 16 questions' responses regards this matter was calculated to get the measure for institutional trust. (Cronbach's alpha = 0.92)

Associational activity is estimated using the answers to WVS's questions of whether the respondent is an active member of various types of groups, from hobby clubs to professional organisations and political parties [45] ranging from the highest of 1 (actively engage) to the lowest of 3 (not attend). Again for better interpretation, the scale was reversed so that 0 stands for no participation while 2 indicating an active member. The results from nine components were averaged to form a unified value for associational activity (Mean $=0.23$; Cronbach's alpha $=0.96)$. It is worth noticing that the average value of associational activity has reduced dramatically compared to what was recorded in the previous waves implying that the number of people attending in groups has reduced during 2005-2009.

Norms of civic behaviour are measured using the WVS' question of whether behaviours such as accepting bribes or cheating on taxes can always be justified, never be justified or something in between [45][94]. The original scale of 1 (never justifiable) to 10 (always justifiable) were reversed so that larger values indicate greater norms of civic behaviour. The results from all four behaviours being surveyed were averaged to get the proxy for this variable. (Cronbach's alpha $=0.92$ ).

3. Moderating variables

Human capital with the measure of the gross tertiary enrolment rate is defined by World Bank (2016) as the total enrolment in tertiary education (ISCED 5 to 8), regardless of age, expressed as a proportion of the total population within five-year age group that followed on from secondary school leaving.

Cultural diversity is measured the 'Ethnic, Linguistic and Religious Fractionalization' index developed by Alesina [5] with three components: ethnic fractionalization, linguistic fractionalization and religious fractionalization. To form a unified variable for cultural heterogeneity, the sum of all three components of the index were averaged.

4. Control variables

Income inequality is measured using the GINI index, which indicates how deviated a country's income distribution among individuals is from a perfectly equal distribution. Therefore, a GINI index of zero denotes perfect equality, while an index of 100 entails perfect inequality.

The total population of the countries (millions of people) was used as a control variable since national innovation is also affected by the number of people within that country [94].

\section{RESULTS}

Computation of variance inflation factor (VIF) suggests no considerable multicollinearity problems (VIF < 2.64). Table 1 depicts the results of multivariate regression models. Amongst the control variables, Model 1 indicates that population has a positively significant effect while income inequality is not significantly correlated to innovation performance. In Model 2 , three out of the four social capital indicators are significantly predictive of innovation performance. While the effects of interpersonal trust and norms of civic behaviour are quite strong, the effect of associational activity is quite modest. Supporting Hypotheses 1, 3 and 4, interpersonal trust ( $\mathrm{p}<$ $.05)$, associational activity $(\mathrm{p}<.10)$, and norms of civic behaviour $(\mathrm{p}<.05)$, respectively, are positively related to innovation performance. For the hypotheses that institutional trust (H2) affects innovation performance, no support is confirmed in the data. Model 3 adds the moderator variables to the prior models.

In Table 1, none of the nation-specific factors engages in a significant effect on innovation performance. The interaction terms created by multiplying the nation-specific factors and the indicators of social capital are introduced in Model 4, indicating that one of the eight interaction effects are significant at the $\mathrm{p}<.05$ level, and other three interactions are significant at the $\mathrm{p}<.10$ level. The negative and relatively significant beta $(\mathrm{p}<.05)$ implies that interpersonal trust is less positively associated with innovation performance when human capital is high, which is inconsistent with Hypothesis 5A. There is no support in the data for Hypothesis 5B indicating human capital does not moderate the relationship between institutional trust and innovation performance. Supporting Hypothesis 5C, the positive and significant $(\mathrm{p}<$ $.05)$ beta for the associational activity $\times$ human capital interaction term shows that associational activity is more positively associated with innovation performance when human capital is high. There is no support for the hypothesis $5 \mathrm{D}$. 
TABLE I:

MODERATED REGRESSION ANALYSIS RESULTS $(\mathrm{N}=51)$

\begin{tabular}{|c|c|c|c|c|}
\hline $\begin{array}{ll}\mathrm{DV}: & \text { Innovation } \\
\text { performance } & \end{array}$ & Model 1 & Model 2 & Model 3 & Model 4 \\
\hline \multicolumn{5}{|l|}{ Step 1: $\quad$ Control } \\
\hline variables & .003 & .024 & .028 & .18 \\
\hline Income inequality & $.002 *$ & $.002 *$ & $.002 * *$ & $.5^{* * *}$ \\
\hline Population & & $* *$ & * & \\
\hline \multicolumn{5}{|l|}{$\begin{array}{l}\text { Step 2: Social capital } \\
\text { indicators }\end{array}$} \\
\hline $\begin{array}{l}\text { Interpersonal trust } \\
\text { (TRUSTA) }\end{array}$ & & $* .022^{*}$ & $.017 *$ & .118 \\
\hline $\begin{array}{l}\text { Institutional trust } \\
\text { (TRUSTB) }\end{array}$ & & .111 & .204 & -.089 \\
\hline Associational activity & & - & - & .113 \\
\hline (GROUP) & & $1.123^{*}$ & $1.177 *$ & \\
\hline $\begin{array}{l}\text { Norms of civic } \\
\text { behaviour (CIVIC) }\end{array}$ & & ${ }_{*} .283^{*}$ & $.328 * *$ & .013 \\
\hline \multicolumn{5}{|l|}{$\begin{array}{l}\text { Step 3: Nation-specific } \\
\text { factors }\end{array}$} \\
\hline Human capital (EDU) & & & .01 & .187 \\
\hline Cultural diversity (DIV) & & & .01 & $.254 *$ \\
\hline $\begin{array}{l}\text { Step 4: Interaction } \\
\text { terms }\end{array}$ & & & & \\
\hline TRUSTA x EDU & & & & $\begin{array}{c}- \\
.587 * *\end{array}$ \\
\hline TRUSTB $x$ EDU & & & & .17 \\
\hline GROUP x EDU & & & & $* .696^{*}$ \\
\hline CIVIC x EDU & & & & -.094 \\
\hline TRUSTA x DIV & & & & $-.369^{*}$ \\
\hline TRUSTB x DIV & & & & -.113 \\
\hline GROUP x DIV & & & & $.72 * *$ \\
\hline CIVIC x DIV & & & & -.198 \\
\hline $\begin{array}{l}\text { Standardized regression } \mathrm{c} \\
* \mathrm{p}<.10 . \\
* * \mathrm{p}<.05 . \\
* * * \mathrm{p}<.01 .\end{array}$ & ficients & eported. & & \\
\hline
\end{tabular}

\section{V.DISCUSSION AND IMPLICATIONS}

\section{A. Discussion}

There has been a major increase in the knowledge-intensive sector of economic endeavour at the global level with the race of technological advancement among nations and massive amount of resources devoted in innovation creations. As human capital continues to be the central source of innovation development [15] more academic and experts' interest has been placed on various human-related notions surrounding these factors within the context of nations. Prior researchers have observed how countries differ in terms of their degree of innovative activity and have mainly adopted Hofstede's [99] cultural dimensions to explain why certain countries innovate more than others. Since the concept of social capital was introduced in the 1980s, numerous researchers have used this factor in clarifying the differences in innovative capability and outcomes between nations. The results, however, have been mixed at dimension-level, reflecting what some scholars have been proposed: the function of social capital is contextual to nation-specific societal factors and depends on social actors' attributes and systems [7]. The current study, which aims to explore the possible elements that condition social capital's explaining effect, furthers research on contextual framework for the concept of social capital in relation with innovation performance across countries.

There is a certain variance of findings at dimension-level compare to previous studies. In the current research, national social indicators of interpersonal trust and norms of civic behaviour are found to positively influence innovation outcomes of particular nation, while institutional trust's impact is not supported. This finding heightens the importance of knowledge exchange in technological creations since the impacts of the two statistically significant aspects are closely characterised by the access to more valuable and larger amount of information only obtained by means of interpersonal interactions, trust and cooperative attitude which is also supported by empirical research of Knack and Keefer [45] and Dakhli and De Clercq [37]. Contrarily, the involvement in social associations is discovered to be significantly negative with innovation outcomes. The similar conclusion was also found by Knack and Keefer [45] implying the overpowering inverse impact of 'self-interest groups' [44] that lobby for preferential policies and keeping the status quo, thus obstruct risky, innovative initiatives. The serious decrease in overall group involvement (the mean value from 1.22 - relatively active member to 0.23 - basically non-member) along with the extant activities of organisations with private purposes may lead to the pessimistic relationship between social relations and innovation outcomes. Moreover, the statistically insignificant impact of institutional trust can be explained by its information-unrelated nature as its main function is the constitution of confidence and willingness to take part in innovative initiatives.

Furthermore, country-specific factors of human capital and cultural diversity only condition the relationships between two social indicators (interpersonal trust and associational activity) and innovation outcomes while manifest neutral effects on the other two relationships (institutional trust and norms of civic behaviour). In the regression, the $\mathrm{R}^{2}$ for the main effects equation (i.e., Model 2) is slightly more than .40 , but that jumps to nearly .70 in the equation where the interaction effects with the human-related variables are included (i.e., Model 4) demonstrating that when combined with certain nation-level socio-cultural conditions that can facilitate or potentially hinder certain innovation-initiating social behaviours, the social capital indicators have, overall, a much more significant influence on innovation performance. While the effect of group involvement on innovation is stronger in a society with highly-educated and culturally diverse population, the explanatory power of interpersonal trust is weakened in such conditions. First, there is a possible justification that more competent individuals are more familiar with and better at identifying correct data sources, have sufficient analytical skills to accurately gather and critically process the complicated information for problem-solving purposes who are less likely to depends on their networks to obtain information and tend to learn and generate ideas independently 
[100][11]. In these circumstances, where there is an increasing number of independent innovators, the role of interpersonal trust between individuals for exchanged information to induce innovation is, to some extent, less important. Second, the finding from the data shows that cultural diversity's negative moderating effect has overwhelmed the positive influence, partially confirming H6A. Therefore, it is suggested that the profits gained from increased variety of information produced by culturally different settings are not sufficient to compensate the resources consumed by training and managing multicultural work force.

\section{B. Implications}

1. Implication for research

First, current theory pertaining to the seemingly ultimate advantages of social capital with little concern about the contextual settings of each society that may variously constitute the extent and functionalities of this form of capital [5][26]. Not all societies benefit from social capital and also not in the same ways as each of them possess different characteristics that may determine how largely it can profit from its social capital.

Second, human capital and cultural diversity are among the distinctive attributes of certain society that are often associated as inherent antecedents of innovation. The possible presumption that immense human capital and cultural diversity may reinforce social capital's effectiveness in promoting innovation is inevitable. However, as revealed in the current study, this should not be a consistent belief.

2. Practical implications

Interpersonal trust and norms of civic are found to foster the innovativeness of the country hence should be improved, mainly through education, for the country to achieve higher innovation performance and then better economic growth.

The level of associational activity can hinder the innovation performance of countries due to the presence of self-interest groups. However, human capital and cultural diversity are found to be able to limit this negative effect of group participation. Thus, improving the educational quality and maintaining high diversity level by formulating immigration policies that promote 'brain gain' can be a good idea for countries with an increase in unwanted associational activities.

As the study found out negative impacts from human capital and cultural diversity on the relationship between interpersonal trust and national innovation performance, policy makers in countries with high level of education and cultural diversity should be able to protect the positive effect of this aspect of their social capital by emphasizing the importance of interpersonal trust in schools along with knowledge and skills to avoid the substitution effect between these positive factors. Moreover, countries characterized by high level of cultural heterogeneity can pursue an equal treatment to all of its citizens to hamper discrimination and facilitate the effectiveness of cross-cultural cooperation.

\section{Limitations and further research}

The role of human capital and cultural diversity in the effect of social capital on fostering innovation at the country level is manifested through the model tested. Even with the additional insights as to the societal benefits and their dynamics discussed, there are a number of limitations. First, in conducting the four main constructs, secondary data sources used cannot fully cover of the domains of the constructs they measure. For example, human capital, often mentioned as the knowledge people hold, could refer to a broad range of domains yet the tertiary enrolment rate used in this study does not fully capture other vocational training and skills as well as the actual survival rate considering possible drop-outs.

This paper proposes a model of social capital and innovation at the societal level with moderating roles of human capital and cultural diversity, in which social capital are to increase innovation under conditions of the two moderators. The evidence for the supportive relationship between social capital and innovation is strong, yet the moderating impacts are mixed. Future longitudinal studies may provide more insights on these relationships. Finally, an area that requires further research can be the explanations of how and why the dimensions create value differently across cultures and regions.

\section{APPENDIX}

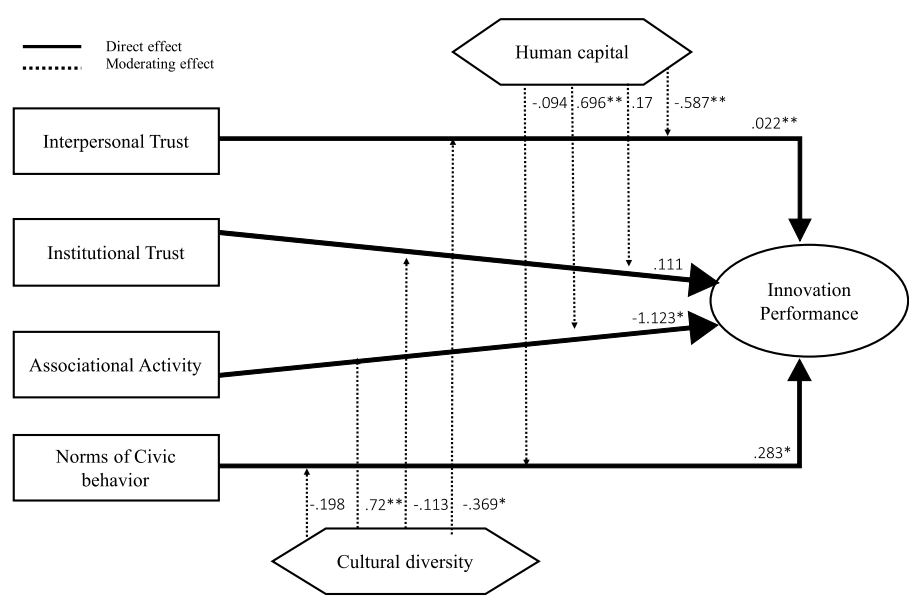

\section{REFERENCES}

[1] Freeman, C. 1987B. Technology Policy and Economic Performance: Lessons from Japan, London, Frances Pinter

[2] Rothwell, R. (1994), "Industrial innovation: success, strategy, trends", in Dodgson, M. and Rothwell, R. (eds.) "The handbook of industrial innovation", Hants : Edward Elgar.

[3] Tura, T., \& Harmaakorpi, V. (2005). Social capital in building regional innovative capability. Regional Studies, 39(8), 1111-1125. Journal Article. http://doi.org/10.1080/00343400500328255

[4] Burt R. S. (2000) The contingent value of social capital, in Lesser E. L. (Ed.) Knowledge and Social Capital: Foundations and Applications, pp. 255-286. Butterworth-Heinemann, Boston, MA. https://doi.org/10.1016/B978-0-7506-7222-1.50014-3

[5] Portes, A.(1998) Social capital: its origins and applications in modern sociology. Annual Review of Sociology 24:1-24. https://doi.org/10.1146/annurev.soc.24.1.1

[6] Bush V. (1945) Science the Endless Frontier. A Report to the President. US Government Printing Office, Washington, DC. 
[7] Putnam, R. (2000) Bowling alone: the collapse and revival of American community. Simon and Schuster, New York. https://doi.org/10.1145/358916.361990

[8] Jones, G., \& Davis, H. (2000). National culture and innovation: Implications for locating global R\&D operations. Management International Review, 40(1), 11-39.

[9] Steensma, H., Marino, L., Weaver, K., \& Dickson, P. (2000). The influence of national culture on the formation of technology alliances by entrepreneurial firms. Academy of Management Journal, 43(5), 951973. JOUR https://doi.org/10.5465/1556421 https://doi.org/10.2307/1556421

[10] Taylor, M. Z., \& Wilson, S. (2012). Does culture still matter?: The effects of individualism on national innovation rates. Journal of Business Venturing, 27(2), 234-247. JOUR. http://doi.org/http://dx.doi.org/10.1016/j.jbusvent.2010.10.001

[11] Nieminen, T., Martelin, T., Koskinen, S., Simpura, J., Alanen, E., Harkanen, T., \& Aromaa, A. (2008). Measurement and SocioDemographic Variation of Social Capital in a Large Population-Based Survey. Social Indicators Research, 85(3), 405-423. JOUR. http://doi.org/10.1007/s11205-007-9102-x

[12] Parts, E. (2013). The dynamics and determinants of social capital in the European Union and neighbouring countries. Discussions on Estonian economic policy: Theory and practice of economic policy in the European Union, (1).

[13] Gächter, S., Herrmann, B., \& Thöni, C. (2004). Trust, voluntary cooperation, and socio-economic background: survey and experimental evidence. Journal of Economic Behavior \& Organization, 55(4), 505531. JOUR. http://doi.org/http://dx.doi.org/10.1016/j.jebo.2003.11.006

[14] Niebuhr, A. (2010). Migration and innovation: does cultural diversity matter for regional R\&D activity?. Papers in Regional Science, 89(3), 563-585 https://doi.org/10.1111/j.1435-5957.2009.00271.x.

[15] Qian, H., \& Stough, R. R. (2011). The effect of social diversity on regional innovation: measures and empirical evidence. International Journal of Foresight and Innovation Policy, 7(1-3), 142-157. JOUR. http://doi.org/10.1504/IJFIP.2011.040071

[16] Schoon, I., Cheng, H., Gale, C. R., Batty, G. D., \& Deary, I. J. (2010). Social status, cognitive ability, and educational attainment as predictors of liberal social attitudes and political trust. Intelligence, 38(1), 144150. https://doi.org/10.1016/j.intell.2009.09.005

[17] Sturgis, P., Read, S., \& Allum, N. (2010). Does intelligence foster generalized trust? An empirical test using the UK birth cohort studies. Intelligence, 38(1), 45-54. https://doi.org/10.1016/j.intell.2009.11.006

[18] Hooghe, M., Marien, S., \& de Vroome, T. (2012). The cognitive basis of trust. The relation between education, cognitive ability, and generalized and political trust. Intelligence, 40(6), 604-613. https://doi.org/10.1016/j.intell.2012.08.006

[19] Schuller, T. (2001). The complementary roles of human and social capital. Canadian Journal of Policy Research, 2(1), 18-24.

[20] Marshall, Melissa and Dietlind Stolle. 2004. "Race and the City. Neighborhood Context and the Development of Generalized Trust." Political Behavior 26 2!: 125-54.

[21] Delhey, J., \& Newton, K. (2005). Predicting cross-national levels of social trust: Global pattern or Nordic exceptionalism? European Sociological Review, 21(4), 311-327. https://doi.org/10.1093/esr/jci022

[22] Anderson, C. and Aida P. (2006). "How Ethnic and Linguistic Heterogeneity Influence the Prospects for Civil Society. A Comparative Study of Citizen- ship Behavior." Journal of Politics 68 4!: 783-802.

[23] Oliver, J. Eric. 2000. "City Size and Civic Involvement in Metropolitan America." Amer- ican Political Science Review 94 2!: 361-73.

[24] Crevoisier, O. and Maillat, D. (1991), "Milieu, industrial organisation and territorial production system: towards a new theory of spatial development", in Camagni, R. (ed.) "Innovation networks: Spatial perspectives", London : Belhaven Press.

[25] Neely, A., \& Hii, J. (1998). Innovation and business performance: a literature review. The Judge Institute of Management Studies, University of Cambridge, 0-65.
[26] Delhey, J., \& Newton, K. (2005). Predicting cross-national levels of social trust: Global pattern or Nordic exceptionalism? European Sociological Review, 21(4), 311-327. https://doi.org/10.1093/esr/jci022

[27] Lundvall B.-A. (Ed.) (1992) National Systems of Innovation: Towards a Theory of Innovation and Interactive Learning. Pinter, London.

[28] Asheim B. (1999) Innovation, social capital and regional clusters: on the importance of co-operation, interactive learning and localised knowledge in learning economies, paper presented at the European Regional Science Association 39th European Congress, Dublin, Ireland, 23-27 August 1999

[29] Edqvist C. (1997) Systems of innovation approaches - their emergence and characteristics, in Edqvist C. (Ed.) Systems of Innovation: Technologies, Institutions and Organizations, pp. 1-35. Pinter, London.

[30] Tura, T., \& Harmaakorpi, V. (2005). Social capital in building regional innovative capability. Regional Studies, 39(8), 1111-1125. Journal Article. http://doi.org/10.1080/00343400500328255

[31] Cooper, D., Doucet, L. and Pratt, M. (2007), "Understanding 'appropriateness' in multinational organizations", Journal of Organizational Behavior, Vol. 28 No. 3, pp. 303-25. https://doi.org/10.1002/job.440

[32] Chell, E. and Baines, S. (2000) Networking, entrepreneurship and microbusiness behaviour, Entrepreneurship \& Regional Development, 12: $195-215$ https://doi.org/10.1080/089856200413464

[33] Dakhli, M., \& De Clercq, D. (2004). Human capital, social capital, and innovation: a multi-country study. Entrepreneurship \& Regional Development, 16(2), 107-128. Journal Article https://doi.org/10.1080/08985620410001677835.

[34] Wiig, H. and Wood, M. (1997), "What comprises a regional innovation system?: Theoretical base and indicators", in Simmie, J. (ed.) "Innovation, networks and learning regions?", p.66-98, The Regional Studies Association.

[35] Florida R. (1995) Toward the learning region, Futures 27, 527-536. https://doi.org/10.1016/0016-3287(95)00021-N

[36] Nelson, R. (ed.) (1993), "National innovation systems: A comparative study", Oxford : Oxford University Press.

[37] Sotarauta M. and Viljamaa K. (2002) Leadership and management in the development of regional innovation environments, paper presented at the 42nd Congress of the European Regional Science Association (ERSA), Dortmund, Germany, 27-31 August 2002.

[38] Nelson R. R. and Nelson K. (2002) Technology, institutions and innovation systems, Research Policy 31, 265-272. https://doi.org/10.1016/S0048-7333(01)00140-8

[39] Dyer, J.H. and H. Singh (1998) The relational view: cooperative strategy and sources of interorganisational competitive advantage. Academy of Management Review 23:660-679. https://doi.org/10.2307/259056 https://doi.org/10.5465/amr.1998.1255632

[40] Nahapiet, J., and S. Ghoshal (1998) Social capital, intellectual capital and the organisational advantage. Academy of Management Review 23:242-266

https://doi.org/10.2307/259373 https://doi.org/10.5465/amr.1998.533225

[41] Fukuyama, F. (1995a) Social capital and the global economy. Foreign Affairs 4.5:89-103. https://doi.org/10.2307/20047302

[42] Putnam, R. (1993) The prosperous community: social capital and public life, The American Prospect, 13: 35-42.

[43] Boix, C. and Posner, D.N. (1998) Social capital: explaining its origins and effects on government performance. British Journal of Political Science 28:686-693. https://doi.org/10.1017/S0007123498000313

[44] Olson, M. (1982) The Rise and Decline of Nations. New Haven: Yale University Press.

[45] Knack, S. and Keefer, P. (1997) Does social capital have an economic payoff? A cross-country investigation, The Quarterly Journal of Economics (November): 1251-1288. https://doi.org/10.1162/003355300555475 
[46] Paxton, P. (1999) Is social capital declining in the United States? A multiple indicator assessment. American Journal of Sociology 105:88127. https://doi.org/10.1086/210268

[47] Schienstock, G., \& Hämäläinen, T. (2001). Transformation of the Finnish innovation system: A network approach. Helsinki: Sitra.

[48] Planque B. (2002) Reflections on innovation networks: contractual vs. 'conventional' networks, paper presented at the 42nd Congress of the European Regional Science Association (ERSA), Dortmund, Germany, 27-31 August 2002.

[49] Zaheer, A., McEvily, B and V. Perrone (1998) Does trust matter? Exploring the effects of interorganisational and interpersonal trust on performance. Organisation Science 9:141-159. https://doi.org/10.1287/orsc.9.2.141

[50] Luhmann, N. (1979) Trust and Power. John Wiley and Sons, Chichester.

[51] Rousseau, D., Sitkin, S., Burt, R. and Camerer, C. 1998 Not so different after all: a cross-discipline view of trust, Academy of Management Review, 23: 393-404. https://doi.org/10.5465/amr.1998.926617

[52] Parsons, T. (1969) Sociological Theory and Modern Society. Free Press, New York

[53] Quin, J. 1979 Technological innovation, entrepreneurship and strategy, Sloan Management Review, 20: 19-30. Ritsila “, J. J. 1999 Regional differences in environments for enterprises, Entrepreneurship \& Regional Development, 11: 187-202.

[54] Oldham, G. R., \& Cummings, A. 1996. Employee creativ- ity: Personal and contextual factors at work. Acad- emy of Management Journal, 39: $607-634$

https://doi.org/10.2307/256657 https://doi.org/10.5465/256657.

[55] Subramaniam, M. and Youndt, M.A. (2005), "The influence of intellectual capital on the types of innovative capabilities", Academy of Management Journal, Vol. 48 No. 3, pp. 450-463. https://doi.org/10.5465/amj.2005.17407911

[56] Tyebee, T. T. and Bruno, A. V. (1984) A model of venture capitalists' investment activity, Management Science, 30: 1051-1066. https://doi.org/10.1287/mnsc.30.9.1051

[57] Kirzner, I. M. 1973. Competition and entrepreneurship. Chi- cago: University of Chicago Press. https://doi.org/10.1111/j.1467-9310.2009.00570.x

[58] Enkel E, Gassmann O and Chesbrough H (2009), Open R\&D and open innovation: exploring the phenomenon, R\&D Management 39(4), pp. $311-316$ https://doi.org/10.1177/0266242612472214

[59] Wynarczyk P, Piperopoulos P and McAdam M (2013) Open innovation in small and medium-sized enterprises: An overview, International Small Business Journal 31(3), pp. 240-255.

[60] Schultz, T.W. "The Value of the Ability to Deal with Disequilibria." J. Econ. Lit. 13, no. 3(September 1975):827-46.

[61] Becker, G. S. (1962). Investment in human capital: A theoretical analysis. The Journal of Political Economy, 70, 9-49. doi:10.1086/258724. https://doi.org/10.1086/258724

[62] Gardner, 1983 H. Gardner Frames of mind: The theory of multiple intelligences Basic Books, New York (1983)

[63] Gardner, 1999b H. Gardner Intelligence reframed: Multiple intelligences for the 21st century Basic Books, New York (1999)

[64] Nelson, R. R. and Phelps, E. S. (1966). 'Investment in Humans, Technological Dif-fusion, and Economic Growth', American Economic Review, Vol. 56, pp. 69-75.

[65] Glaeser, E. L., Laibson, D. I., Scheinkman, J. A., \& Soutter, C. L. (2000). Measuring trust. The Quarterly Journal of Economics, 115(3), 811-846. https://doi.org/10.1162/003355300554926

[66] Landry R., Amara N. \& Lamari M. (2002) Does social capital determine innovation? To what extent?, Technological Forecasting and Social Change 69, 681-701. https://doi.org/10.1016/S0040-1625(01)00170-6

[67] Romer, P. 1986. Increasing returns and long-run growth, Journal of Political Economy, vol. 94, no. 5, 1002-37 https://doi.org/10.1086/261420
[68] Johanssen B., Karlsson C. \& Stough R. (Eds) (2001) Theories of Endogenous Regional Growth: Lessons for Regional Policies. Springer, Berlin https://doi.org/10.1007/978-3-642-59570-7.

[69] Lee, S. Y., Florida, R., \& Gates, G. (2010). Innovation, Human Capital, and Creativity. International Review of Public Administration, 14(3), 13-24. JOUR. http://doi.org/10.1080/12294659.2010.10805158

[70] Teles, V. K., \& Joiozo, R. (2011). Human capital and innovation: evidence from panel cointegration tests. Applied Economics Letters, 18(17), 1629-1632. JOUR. http://doi.org/10.1080/13504851.2011.556584

[71] Sternberg, R.G., 1995. Government R\&D expenditure and space: empirical evidence from five industrialized countries. Research Policy $25,741-758$ https://doi.org/10.1016/0048-7333(95)00860-8

[72] Gardner, H. (1993). Multiple Intelligences: The Theory in Practice. New York: Basic Books.

[73] Furnham, A., \& Hogan, R. T. (2006). Competencies and character (unpublished work).

[74] Devine, D. and Philips, J. (2001), "Do smarter teams do better: a metaanalysis of cognitive ability and team performance", Small Group Research, Vol. 32 No. 5, pp. 507-32. https://doi.org/10.1177/104649640103200501

[75] Yeager, K. L., \& Nafukho, F. M. (2012). Developing diverse teams to improve performance in the organizational setting. European Journal of Training and Development, 36(4), 388-408. https://doi.org/10.1108/03090591211220320

[76] Hoffman, L. R., \& Maier, N. R. (1961). Quality and acceptance of problem solutions by members of homogeneous and heterogeneous groups. The Journal of Abnormal and Social Psychology, 62(2), 401.

[77] Janis, I. L. 1982. Groupthink: Psychological studies of policy decisions and fiascos. Boston: Houghton Mifflin.

[78] Schumpeter, Joseph A. Capitalism,Socialism, and Democracy.New York: Har- per, 1942.

[79] Damanpour, F., \& Schneider, M. (2009). Characteristics of innovation and innovation adoption in public organizations: Assessing the role of managers. Journal of public administration research and theory, 19(3), 495-522. https://doi.org/10.1093/jopart/mun021

[80] Shariff, M. N. M., \& Saud, M. B. (2009). An attitude approach to the prediction of entrepreneurship on students at institution of higher learning in Malaysia. International Journal of Business and Management, 4(4), 129. https://doi.org/10.5539/ijbm.v4n4p129

[81] Gurel, E., Altinay, L., \& Daniele, R. (2010). Tourism students' entrepreneurial intentions. Annals of Tourism Research, 37(3), 646-669. https://doi.org/10.1016/j.annals.2009.12.003

[82] Lazear, E. P. (1999). Globalisation and the market for team-mates. The Economic Journal, 109(454), 15-40. https://doi.org/10.1111/1468-0297.00414

[83] Landry, Charles (2000): The Creative City. London, Earthscan.

[84] Howkins, John (2002): The Creative Economy. How People make money from Ideas. Penguin Book.

[85] Hartley, John (2007): Creative Industries. London, Wiley Blackwell.

[86] Florida, Richard (2004): The Rise of the Creative Class. New York, Basic Books.

[87] Westwood, R. and Low, D.R. (2003), "The multicultural muse culture, creativity and innovation", International Journal of Cross Cultural Management, Vol. 3 No. 2, pp. 235-259. https://doi.org/10.1177/14705958030032006

[88] Harrison, D., Price, K., Gavin, J. and Florey, A. (2002), "Time, teams, and task performance: changing effects of surface- and deep-level diversity on group functioning", Academy of Management Journal, Vol. 45 No. 5, pp. 1029-45. https://doi.org/10.5465/3069328 https://doi.org/10.2307/3069328

[89] Olson, B., Parayitam, S. and Bao, Y. (2007), "Strategic decision making: the effects of cognitive diversity, conflict, and trust on decision outcomes", Journal of Management, Vol. 33 No. 2, pp. 196-222 https://doi.org/10.1177/0149206306298657. 
[90] van den Bossche, P., Gijselaers, W., Segers, M., Woltjer, G. and Kirschner, P. (2011), "Team learning: building shared mental models", Instructional Science, Vol. 39 No. 3, pp. 283-301. https://doi.org/10.1007/s11251-010-9128-3

[91] Doring, H. (1992) Higher education and confidence in institutions: a secondary analysis of 'European Values Survey', 1981-83, West European Politics, 15: 126-146. https://doi.org/10.1080/01402389208424910

[92] Kogut, B., \& Zcmder, U. 1996. What d o firms do? Coordination, identity and learning. Organization Science, 7: 502-518. https://doi.org/10.1287/orsc.7.5.502

[93] Patsiurko Natalka, John L. Campbell and John A. Hall (2012). "Measuring cultural diversity: ethnic, linguistic and religious fractionalization in the OECD". Ethnic and Racial Studies. 35 (2): 195 217.doi:10.1080/01419870.2011.579136. Retrieved September 13, 2016. https://doi.org/10.1080/01419870.2011.579136

[94] Dakhly, M., \& De Clercq, D. (2004). Human capital, social capital, and innovation: a multi-country study. Entrepreneurship \& Regional Development, 16(2), 107-128. Journal Article. http://doi.org/10.1080/08985620410001677835

[95] Ritsila, J. J. (1999) Regional differences in environments for enterprises, Entrepreneurship \& Regional Development, 11: 187-202. https://doi.org/10.1080/089856299283164

[96] Smallbone, D. and North, D. (1997) Innovation and new technology in rural SMEs, paper presented to the 20th ISBA National Small Business Conference, Belfast, 19-21 November.

[97] Nadvi, K. (1997) The cutting edge: collective efficiency and international competitiveness in Pakistan's surgical instruments sector, Institute of Development Studies (June).

[98] Kalantaridis, C. and Pheby, J. (1999) Process of innovation among manufacturing SMEs: the experience of Bedfordshire, Entrepreneurship \& Regional Development, 11: 57-78. https://doi.org/10.1080/089856299283290

[99] Hofstede, G. 1980 Culture's Consequences: International Differences in Work Related Values (Beverly Hills, CA: Sage).

[100]Percy, K. A. and Salter, F. W. (1976). 'Student and staff perceptions and "the pursuit of excellence" in British higher education', Higher Education 5: 457-473.

https://doi.org/10.1007/BF01680080 